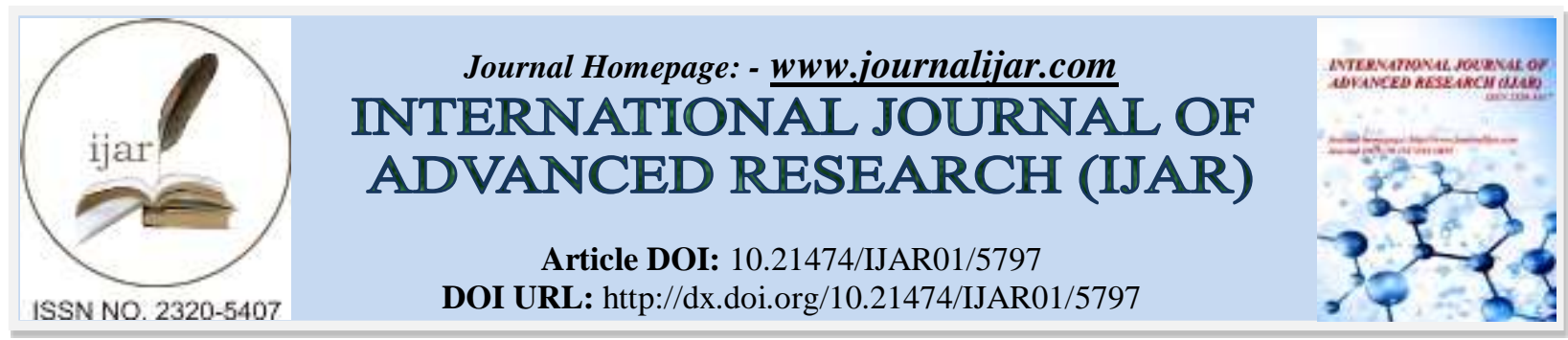

RESEARCH ARTICLE

\title{
STUDY THE EFFECT OF ASPECT RATIO AND INLET CONFIGURATIONS ON THE HYDRAULIC OF BOX CULVERT UNDER INLET CONTROL.
}

\author{
Jaafar S. Maatooq ${ }^{1}$, Hassan A. Omran ${ }^{2}$ and Mayssam M. Taha ${ }^{3}$. \\ 1. Assistant Professor of Hydraulic Structures, Building and Construction Engineering Dept., University of \\ Technology, Baghdad, Iraq. \\ 2. Assistant Professor of Water Resources, Building and Construction Engineering Dept. University of \\ Technology, Baghdad, Iraq. \\ 3. MSc. Student, Building and Construction Engineering Dept., University of Technology, Baghdad, Iraq.
}

\section{Manuscript Info}

\section{Manuscript History}

Received: 07 September 2017

Final Accepted: 09 October 2017

Published: November 2017

Key words:-

box culvert; inlet control; submerged entrance; inlet transition; culvert barrel.

\begin{abstract}
The feature and configuration of culvert entrance beside the aspect ratio (span/rise) have a key role in determining the hydraulic performance of culver. The conveyance along with the permitted height of head water can be determined mainly by the effect of the entrance factors on it. The present study aim to investigate the entrance feature and configuration on the hydraulic performance of culvert operated at inlet control for both unsubmerged and submerged entrance. Different aspect ratios with just head wall of square edges entrance have been tested experimentally by a wide range conditions to perform both unsubmerged and submerged flow. However, a new shape of inlet transition structure that proposed by Howes et al., 2010 have been adopted as the inlet approach to achieve a gradual contraction of stream lines before entrance. The results showed that improvement in performance through adoption of the actual measurements of contraction coefficients which leads to extract a new practical equations and design charts. However, the traditional limitations of the zone between unsubmerged and submerged flow at the entrance were developed through using a new shape of the inlet transition as the approach section to square edges entrance.
\end{abstract}

Copy Right, IJAR, 2017,. All rights reserved.

\section{Introduction:-}

A culvert is a structure through which storm water is drained from one side of an embankment to the other. There are two aspects to the design of a culvert; the first is the hydraulic aspect at which the culvert should be able to convey the design discharge with water level on the upstream side as low as possible, whereas the second is the structural aspect. The hydraulic aspect deals with the flow feature through culvert, it may be under inlet or outlet control. Inlet control occurs when the culvert barrel is capable to convey more flow than the inlet will accept, at which the control section is located just inside the entrance, and the hydraulic characteristics downstream this section do not affect the culvert capacity. The flow rate depends only on size and shape of the cross section (aspect ratio) and the entrance conditions (such as square edged or splayed, etc.) (Dasika, 1995). However, the outlet control flow occurs when the culvert barrel is not capable to convey as much flow as the inlet opening will accept. At this feature of flow the control section is located at the barrel exit or further downstream. When achieving the outlet 
control all of the geometric and hydraulic characteristics of the culvert play a role in determining its capacity (Bodhaine, 1988, Dasika, 1995, Schall et al., 2012). It was initially hypothesized that poor inlet conditions, causing flow separation at the entrance that lead un-efficient velocity distributions for flow measurement. Thus the objective of designer is to decrease the flow separation. The transition structure with suitable shape when it used at entrance can be considered a success feature to achieve this objective. The transition when used at the entrance of the culvert will provide a smooth change in channel cross section and it is avoid unnecessary head lose through change in cross section. In present study the inlet shape that recommended by Howes et al., 2010 was used as the transition to the entrance of culvert. This usage is a trial aims to reduce the poor inlet condition of square edge of head wall that has widely been used in practice which considered the main reason on flow separation at entrance.

\section{Experimental work:-}

The flume available in hydraulic laboratory of Building and Construction Engineering Department with measurements facilities and devices are used for experimental program. The dimensions of flume are $30 \mathrm{~cm}$ in width, $12 \mathrm{~m}$ in length and its depth is $40 \mathrm{~cm}$. The channel sides were made from toughened glass along the entire length. The centrifugal pump is used to supplying different discharges with the maximum rate $\left(110 \mathrm{~m}^{3} / \mathrm{hour}\right)$. A platform of plastic sheet $0.8 \mathrm{~cm}$ in thickness and $200 \mathrm{~cm}$ in length is installed into flume at slope 0.02 to simulate the bed of culvert model. Two sheets of the plaxi-glass are installed over the platform simulate the side walls of culvert model. However, $30 \mathrm{~cm} \times 30 \mathrm{~cm}$ square sheets are manufactured with a specified square edge opening and installed as the head wall. The opening of the head wall consisted three span equal $10 \mathrm{~cm}, 15 \mathrm{~cm}$ and $20 \mathrm{~cm}$ and denoted as B along with nine variable rises equal to $5 \mathrm{~cm}, 6 \mathrm{~cm}, 7 \mathrm{~cm}, 7.5 \mathrm{~cm}, 8.5 \mathrm{~cm}, 10 \mathrm{~cm}, 15 \mathrm{~cm}, 20 \mathrm{~cm}$ and $25 \mathrm{~cm}$ and denoted as $\mathrm{D}$, these openings enables twelve aspect ratios $\mathrm{B} / \mathrm{D}=0.4,0.5,0.75,1,1.176,1.33,1.429,1.67,2,2.5,3.33$ and 4. With these values of $\mathrm{B} / \mathrm{D}$ it can achieve wide range of aspect ratios those may encounters in practice and such a range however, are not investigated before in literature. For each aspect ratio (i.e., span/rise) different discharges has been adopted to give a wide range of operation of the culvert hydraulics for both submerged and un-submerged entrance under inlet control. This control was achieved after adjusting the tail gate of the flume to insure the supercritical flow along the culvert length. The velocities and depths were measured along the culvert for different discharges after flow become steady. Fig.1 illustrates the view of one of the culvert model after installation into the flume with head wall. After all runs completed with head wall only, the configuration of inlet contraction which proposed by Howes et al., 2010 as shown in Fig. 2 was adopted and installed as the inlet transition with head wall (see Fig. 3). This adoption aims to enhance the hydraulic performance of culvert. The same aspect ratios and hydraulic conditions for head wall have been repeated after installing the transition and all necessary measurements were conducted accordingly.

\section{Results and Discussion:-}

The flow entering into the culvert was at varying rates ranging from 0.00546 to $0.0262 \mathrm{~m}^{3} / \mathrm{s}$. Basically, as the discharge increase the headwater is accordingly increase for the same B/D. First of all, the operation has been conducted for culvert with headwall of square edge. However, with installation the transition for each B/D, the headwater decreases gradually for the same discharges which mean the better performance. When the culvert entrance is unsubmerged the contraction of the flow at the entrance of square edge became clearly affect the measuring of the effective width. The contraction coefficient associated with the culvert entrance edge conditions $\mathrm{C}_{\mathrm{b}}$ can be calculated by the following equation which proposed by Charbeneau et al., 2006 based on energy equation between section of head water and the contracted section;

$\frac{H W}{D}=\frac{3}{2}\left(\frac{1}{C_{b}}\right)^{2 / 3}\left(\frac{Q}{A \sqrt{g D}}\right)^{2 / 3}$

This equation proposed that the head water is equal to the critical specific energy at the control section within the culvert entrance at which the contraction is appears and $\mathrm{Cb}$ coefficient is achieved. That is true theoretically where the head loss between the head water and the control section is negligible. In practice this assumption may not true because of lack of locating the control section just at entrance exactly as a results of real fluid flow and entrance feature. In present study there is a trial to measure $\mathrm{Cb}$ exactly at the location of the effective width of flow that is located at the center of turbulence region as shown in Fig. 4. The experimental work has confirmed that the section of achievement of $\mathrm{Cb}$ was not specified. Thus it should develop the correlation of the relationship between the dependent and undependent variables of Eq.1. 
When the culvert entrance is submerged the coefficient $\mathrm{Cc}$ is created due to the contraction of flow after passing the upper edge of culvert as shown in Fig.5. This coefficient can be calculated by the Eq.2 which also proposed by Charbeneau et al., 2006.

$\frac{H W}{D}=\frac{1}{2\left(C_{b} C_{c}\right)^{2}}\left(\frac{Q}{A \sqrt{g D}}\right)^{2 / 3}+C_{c}$

As explained for Eq.1, the Eq.2 should also be developed based on the experimental results of the present study. For the same geometric and flow conditions the higher the values of $\mathrm{Cb}$ and $\mathrm{Cc}$ coefficient the less region of turbulence and the efficient performance of culvert accordingly. This target is achieved with highly efficient entrance feature of culvert.

Fig. 6 illustrate the differences between contracted coefficients those calculated by Eq. 1 and the measured from experiments for unsubmerged entrance with $\mathrm{B} / \mathrm{D}=0.4$ and 0.5 . As can be seen the higher values that resulted from experiments and the greater of these have been recorded with using the transition. In order to be in the same as the context of Eq.1, the developed form of the relationship between the head water and the discharge based on the experimental results become;

$\frac{H W}{D}=1.719\left(\frac{1}{C_{b}}\right)^{0.095}\left(\frac{Q}{A \sqrt{g D}}\right)^{0.5407}$

$\frac{H W}{D}=1.7823\left(\frac{1}{C_{b}}\right)^{-0.2417}\left(\frac{Q}{A \sqrt{g D}}\right)^{0.5068}$

Eq.3-a used with square edge head wall as the entrance of culvert for both $\mathrm{B} / \mathrm{D}=0.4$ and 0.5 , while the Eq.3-b can adopted when using head wall with transition for $B / D=0.5$. The determination coefficients $\mathrm{R}^{2}$ of these equations are 0.9864 and 0.9924 respectively. The high value of $\mathrm{R}^{2}$ refers to a good correlation between dependent and independent variables which leads to the less error when using Eq.3 for calculation, this conclusion is well illustrated in Fig. 7.

To use Eq.3 for design considerations it should be firstly know the value of the contraction coefficient $\mathrm{Cb}$ for the specified condition under study. In practice if the calculation of head water of known riser culvert is given it become easy to use Fig. 8 to find the value of $\mathrm{Cb}$ according to the entrance feature or from the following equations;

$$
\begin{aligned}
& C b=-2.477\left(\frac{H w}{D}\right)^{3}+6.763\left(\frac{H w}{D}\right)^{2}-6.131\left(\frac{H w}{D}\right)+2.625 \\
& C b=1.45\left(\frac{H w}{D}\right)^{3}-5.677\left(\frac{H w}{D}\right)^{2}+7.252\left(\frac{H w}{D}\right)-2.362 \\
& C b=-3.752\left(\frac{H w}{D}\right)^{3}+11.608\left(\frac{H w}{D}\right)^{2}-11.529\left(\frac{H w}{D}\right)+4.523
\end{aligned}
$$

The three parts of Eq. 4 are used with aspect ratios B/D=0.4 and B/D=0.5 with square edge head wall, and B/D=0.5 with square edge head wall and transition respectively. The determination coefficients $R^{2}$ of Eq.4a to $4 \mathrm{c}$ are 0.822 , 0.959 and 0.926 . Then it becomes possible to use the Eq. 3 for finding the amount of discharge.

Based on the experimental data of the present study it can simply using Figs. 9 and 10 to determine the flow that could safely directed into the culvert for the aspect ratio as indicated in the description legends of these figures for square edge entrance without transition and with transition respectively under unsubmerged condition. The correlation equations of these figures with $\mathrm{R}^{2}=0.9905$ and 0.961 are respectively;

$\frac{H w}{D}=1.652\left(\frac{Q}{A \sqrt{g D}}\right)+0.409$

$\frac{H w}{D}=0.55 e^{1.709\left(\frac{Q}{A \sqrt{g D}}\right)}$

Where, $\mathrm{A}$ is the product of span times the rise (cross sectional area of the culvert entrance).

When the entrance of culvert become submerged (at high head water) the vertical contraction coefficient Cc is created beside the $\mathrm{Cd}$. The theoretical feature of the relationship between head water and discharge which presented by Eq. 2 should examined according to the results within the limitations and the boundary conditions of the present study. The following equation is a result of the correlation between the head water and discharge when the configuration of culvert entrance was square edge head wall without transition with $\mathrm{R}^{2}=0.978$; 
$\frac{H w}{D}=1.824(C b C c)^{0.158}\left(\frac{Q}{A \sqrt{g D}}\right)^{1.443}+1.138 C c$

The form of Eq.7 is similar to the form of Eq.2 which presented by Charbeneau et al., 2006 but with different coefficients and exponents. These differences is due to the fact that the results of the application diverge from the hypothesis that the head water is equal to the critical specific energy at the control section located just at the culvert entrance that which means the head loss between the head water and the control section is negligible. The formula of Eq.7 can be applicable for aspect ratios B/D located between 0.5 and 1.67.

The coefficients $\mathrm{Cc}$ and $\mathrm{Cb}$ should be known before using the formula of Eq. 7 as a deterministic equation. These coefficients have been correlated with aspect ratio of culvert entrance B/D as shown in Fig. 11. The relevant equations can be included as follows;

$C_{c}=-0.415\left(\frac{B}{D}\right)^{3}+1.375\left(\frac{B}{D}\right)^{2}-1.333\left(\frac{B}{D}\right)+0.993$

$C_{b}=0.065\left(\frac{B}{D}\right)+0.77$

The $\mathrm{R}^{2}=0.708$ and 0.931 respectively.

Instead of the form of Eq.7, it could use the following polynomial equation correlated based on the hydraulic and the geometric boundary conditions of the present study with $\mathrm{R}^{2}=0.9776$ or using Fig.12;

$\frac{H w}{D}=0.553\left(\frac{Q}{A \sqrt{g D}}\right)^{2}+1.36\left(\frac{Q}{A \sqrt{g D}}\right)+0.484$

When the transition used as the approach section to the square edged entrance of culvert the following equation can be adopted instead of Eq.7 with $\mathrm{R}^{2}=0.9777$;

$\frac{H w}{D}=1.603(C b C c)^{-0.003}\left(\frac{Q}{A \sqrt{g D}}\right)^{1.716}+1.281 C c$

While the contraction coefficients $\mathrm{Cc}$ and $\mathrm{Cb}$ can be taken from Fig.13 or by using the following equations;

$C_{c}=-0.0087\left(\frac{B}{D}\right)^{3}+0.0396\left(\frac{B}{D}\right)^{2}+0.0037\left(\frac{B}{D}\right)+0.6404$

$C_{b}=0.0232\left(\frac{B}{D}\right)+0.8951$

The determination coefficients, $\mathrm{R}^{2}$, of these equations are 0.42 and 0.4 respectively. The interpretation of a weak correlation between the contraction coefficients and the aspect ratio $\mathrm{B} / \mathrm{D}$ can be attributed to that the contraction of streamlines begin within the transition reach before entering to the culvert which refers to a negligible influence of the culvert entrance edges. Accordingly, with using a transition as the approach section to the culvert entrance, the form of Eq.11 becomes meaningless. Thus it needs to use the most appropriate formula in practical application to becomes more reliable when using the transition as that which adopted in present study. This more realistic formula with $\mathrm{R}^{2}=0.9819$ is;

$\frac{H w}{D}=1.1323\left(\frac{Q}{A \sqrt{g D}}\right)^{2}+0.597\left(\frac{Q}{A \sqrt{g D}}\right)+0.785$

The Fig.14 is a substituted for the Eq.13 when use it in the application. It should be mentioned that Eq.14 or Fig.14 can be applicable for the aspect ratios B/D ranged between 0.5 and 4 .

It has been through the experimental program the aspect ratios $\mathrm{B} / \mathrm{D}=0.5,0.75$ and 1.33 with using transition are the only through which the two types of flow (unsubmerged and submerged) are accessible. The analysis of data shows that the transition zone between the two types of performance was at $\mathrm{Hw} / \mathrm{D}=1.3$ and $\mathrm{Q} / \mathrm{A} \sqrt{\mathrm{gD}}=0.55$, this limiting value of headwater related to the riser is well agreement with this proposed by Bowers et al., 1953. The Fig. 15 or the following formulas can be used for design consideration within the acceptance reliability where $R^{2}=0.9766$ for unsubmerged flow and $\mathrm{R}^{2}=0.8465$ for submerged flow respectively.

$\frac{H w}{D}=1.602\left(\frac{Q}{A \sqrt{g D}}\right)+0.455$

$\frac{H w}{D}=3.302\left(\frac{Q}{A \sqrt{g D}}\right)^{2}-2.1815\left(\frac{Q}{A \sqrt{g D}}\right)+1.559$

As stated by Charbeneau et al, 2006, the transition between unsubmerged and submerged condition for the box culvert with head wall and square edge entrance can be expressed through the following equations;

$\frac{H_{w}}{D}=1.5 C c$ 
$\frac{Q}{A \sqrt{g D}}=C_{b} C_{c}{ }^{1.5}$

With using the average values of the experimental results for both $\mathrm{Cc}$ and $\mathrm{Cb}$ when culvert operated under the effect of the approach transition into Eqs.17 and 18 the resulted values of the left hand side for a transition zone are 1.082 and 0.577 respectively. The results of the present study show a higher limit of Hw/D whereas the less has been recorded for the second term to become a boundary limit between unsubmerged and submerged flow conditions. That is refer when the transition structure is used as the approach feature to the culvert entrance a higher head water with the lower discharge can be pass to the culvert barrel at unsubmerged condition as compared to the entrance when just equipped with head wall.

In FHWA and USGS manuals of culvert the unsubmerged entrance flow are distinguished by the head water elevation being less than 1.5 the culvert diameter. However, the submerged entrance flows are distinguished by the head water elevation being greater than or equal to the 1.5 culvert diameter as stated by Chin, 2013. The limiting value of Hw/D for present study did not come compatible with those proposed by USGS and FHWA. This divergence can be attributed to that the previously proposed limitations are mainly built on the hydraulic performance for circular entrance culvert.

\section{Conclusions:-}

The present study has been investigated the effect of the entrance feature and configuration with the wide range of aspect ratios (span/rise) on the hydraulic performance of box culvert operated at inlet control for both unsubmerged and submerged entrance. The contraction coefficients those created at the entrance of culvert due to the feature of inlet design and the effect of the aspect ratio for both unsubmerged and submerged flow has been measured experimentally and compared with literatures and a modification factors along with relevant charts and design equations are proposed. To improve the effect of entrance on the hydraulic performance of culvert the attempt was follow to introduce the well streamlined inlet transition as recommended by Howes et al., 2010 to become the approach section to the square edged entrance with head wall. The results for this attempt were an encouraging and need more research.

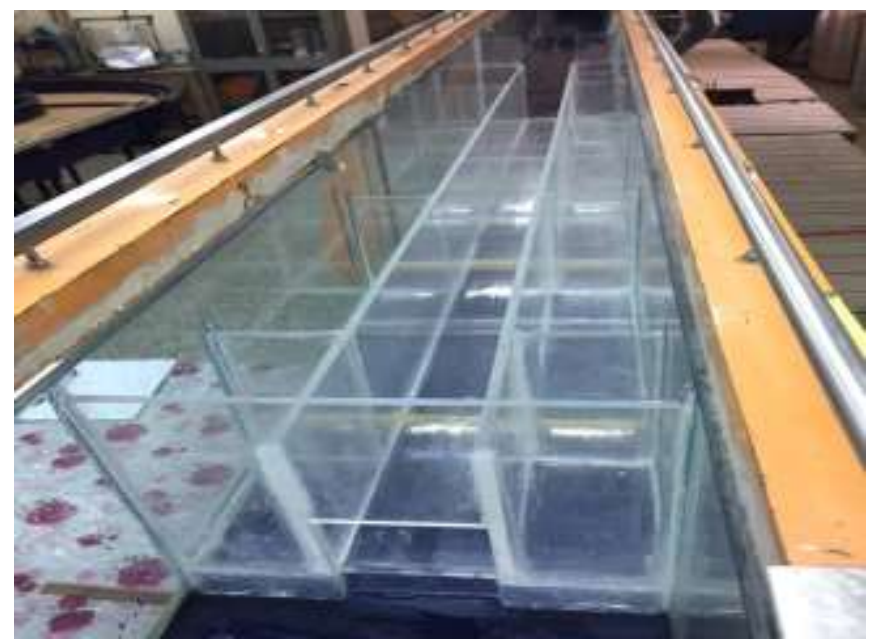

Figure 1:- View of the culvert model after installation into the flume with head wall. 


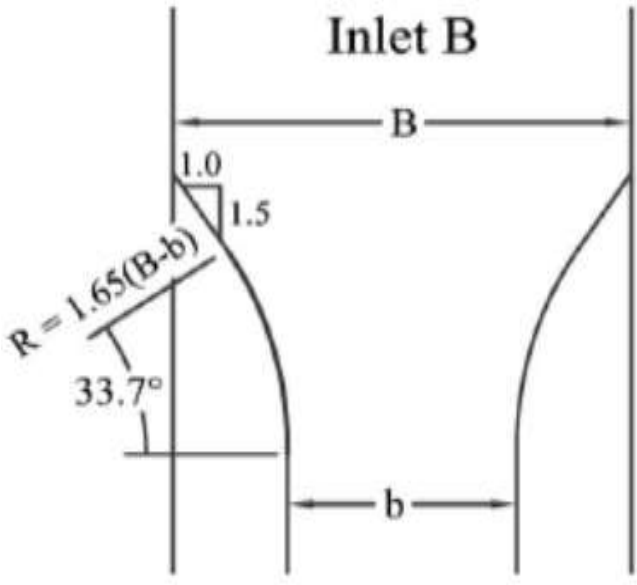

Figure 2:- Inlet transition configuration as proposed by Howes et al.,2010

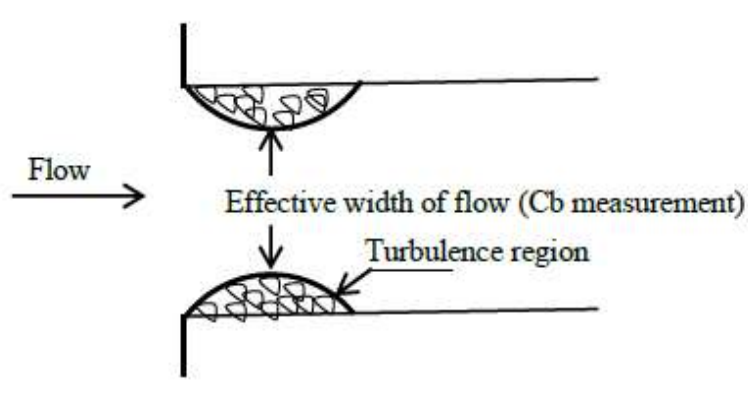

Figure 4:- Effective width of flow at the center of turbulance region

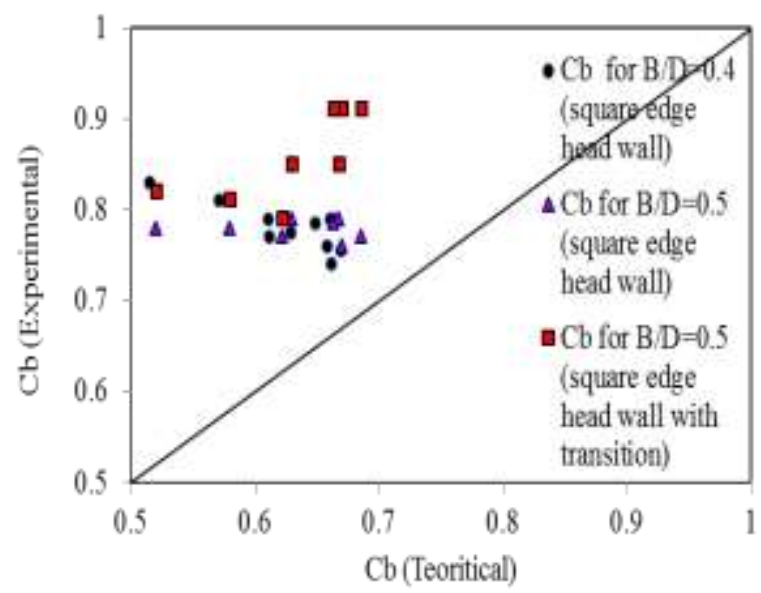

Figure 6. The difference between theoritical and measured value of $\mathrm{Cb}$ fro different entrance configurations

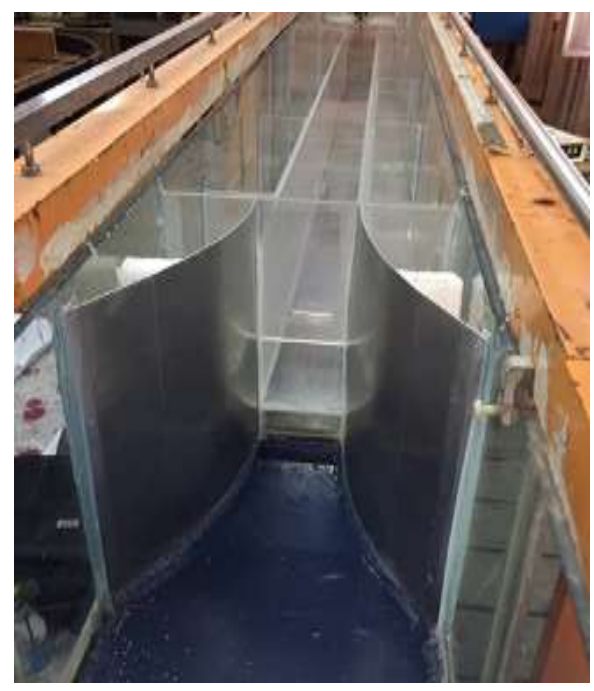

Figure 3:- Howes, 2010 transition after installed at entrance of culvert model

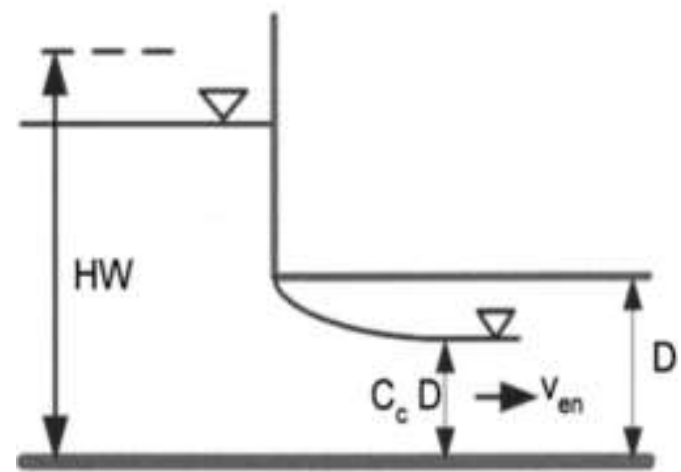

Figure 5:- Vertical contraction due to submerged entrance (Charbeneau et al., 2006)

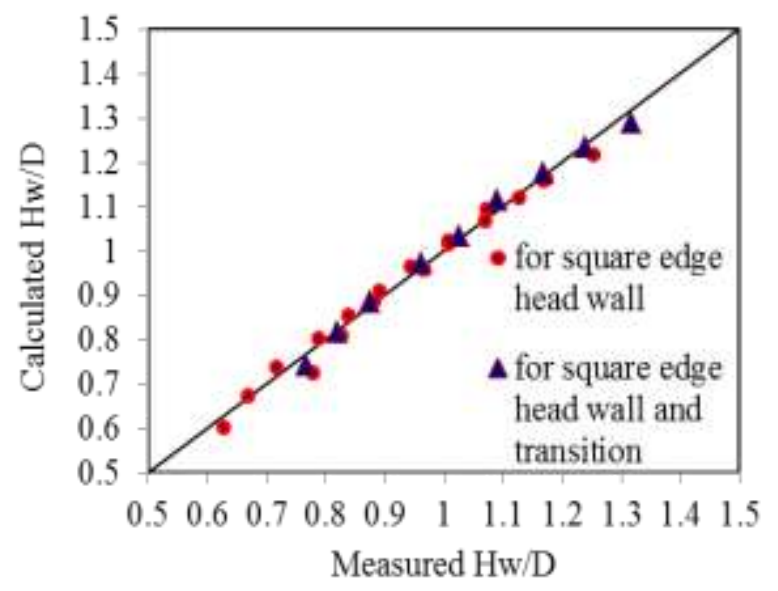

Figure 7. The relation between measured and calculated value of head water by using Eq. 3 


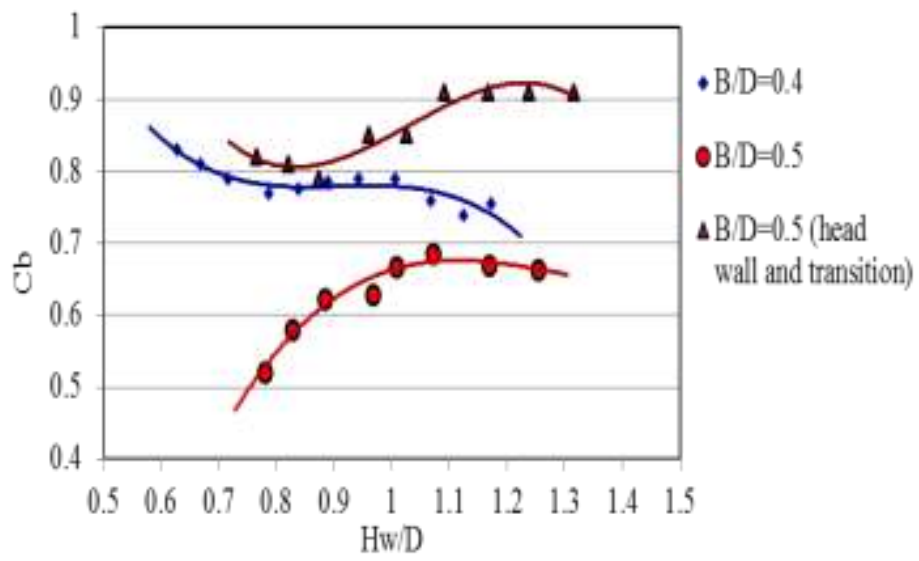

Figure 8. Design Curve to calculate Cb for unsubmerged flow condition

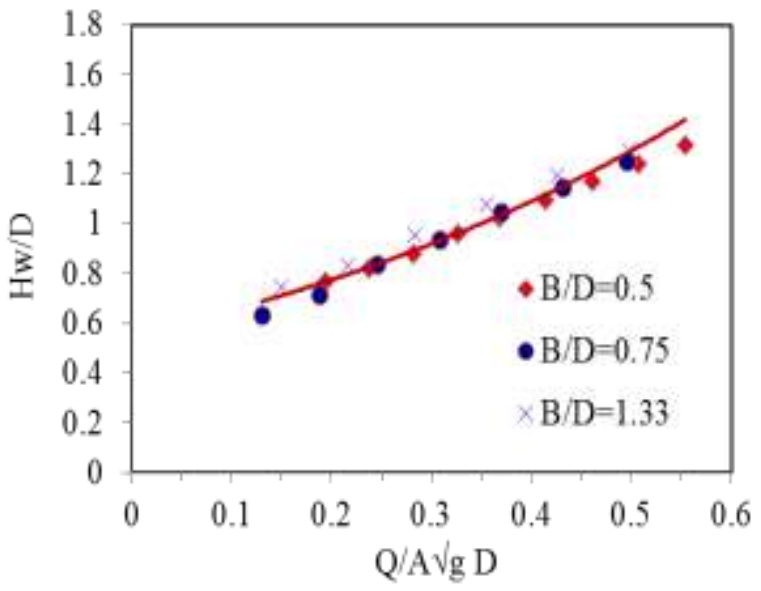

Figure 10. Practical Relationship between Headwater and Discharge for square edge with apprach transition at unsubmerged flow condition

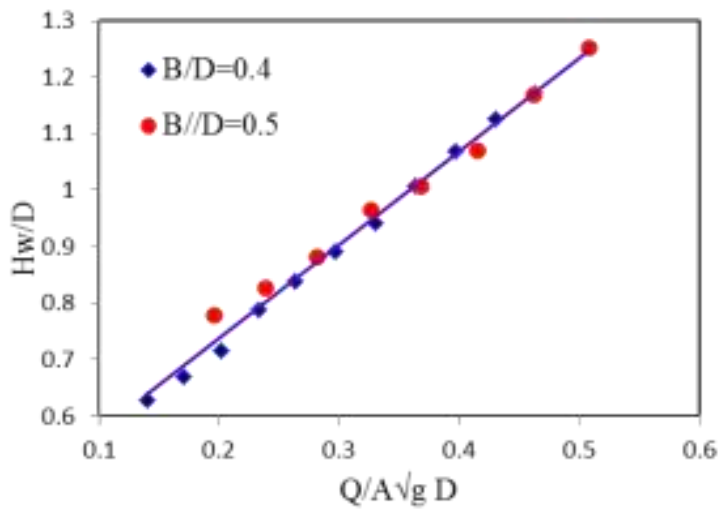

Figure 9. Practical Relationship between Head water and Discharge for Square edge entrance with head wall at unsubmerged flow condition

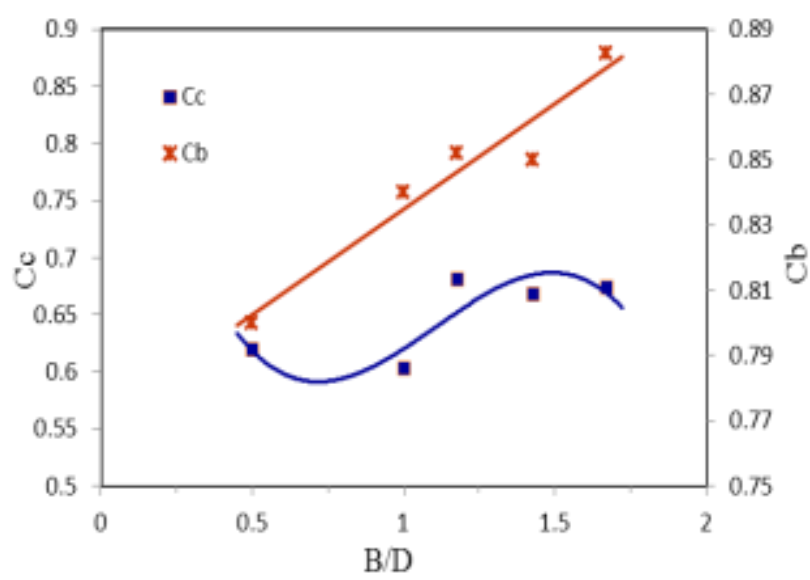

Figure 11. Desighn Curves to Calculate $\mathrm{Cc}$ and $\mathrm{Cb}$ for submerged flow condition

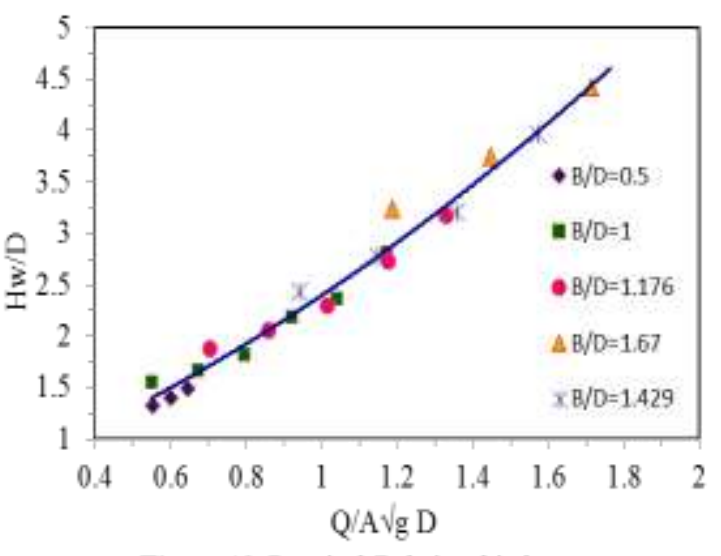

Figure 12. Practical Relationship between Headwater and Discharge for square edge entrance with head wall at submerged flow condition

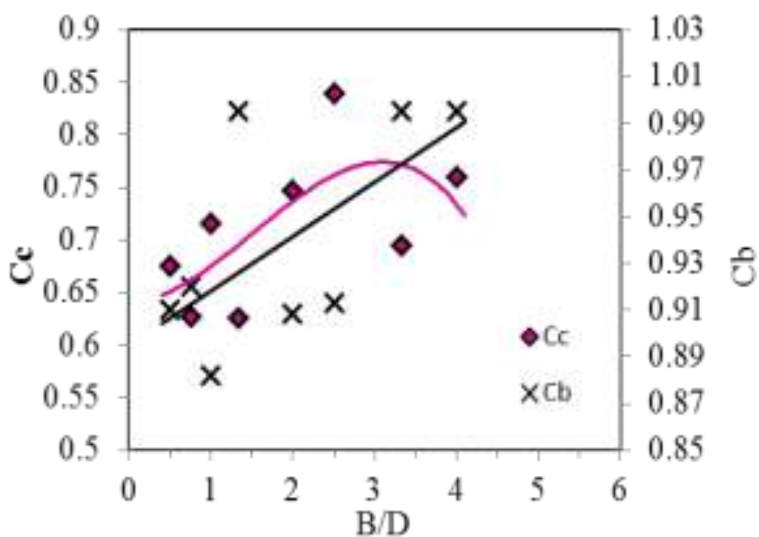

Figure 13. Design Curve to Calculate $\mathrm{Cc}$ and $\mathrm{Cb}$ for submerged flow at entrance with using inlet transition 


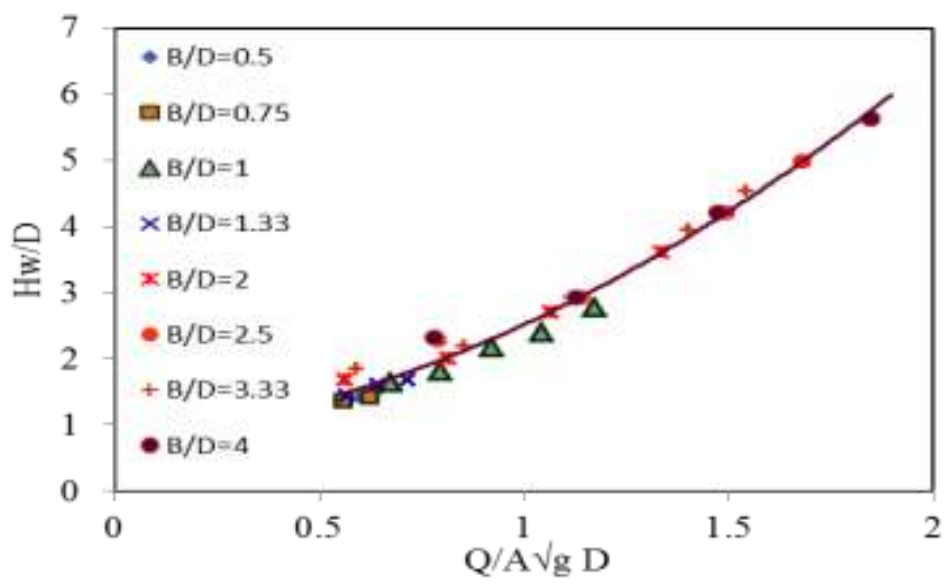

Figure 14. Practical Relationship between

Headwater and Discharge for Square edge entrance with inlet transition at submerged flow condition

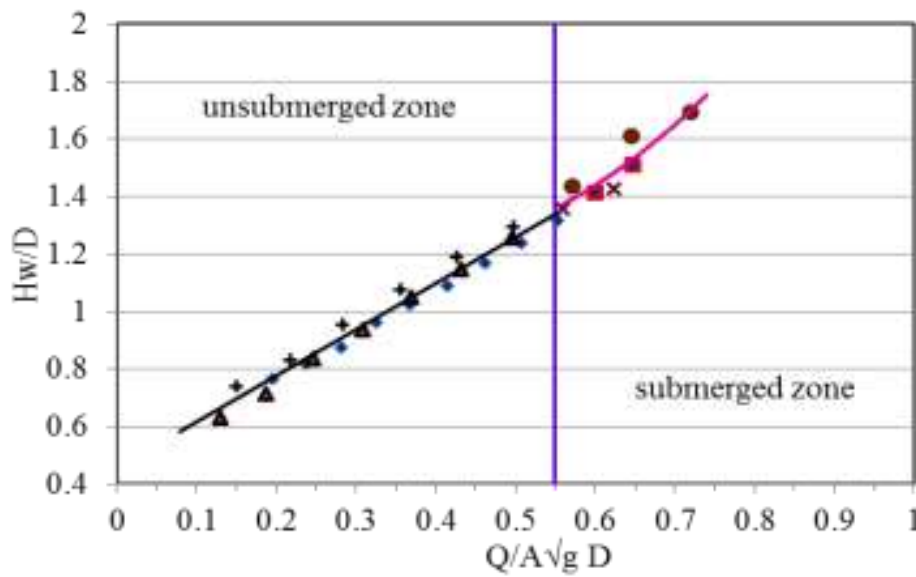

$$
\begin{aligned}
& -\mathrm{B} / \mathrm{D}=0.5 \text { (free flow } \\
& \text { entrance) } \\
& \mathrm{B} / \mathrm{D}=0.5 \text { (submerged } \\
& \text { flow entrance) } \\
& \Delta \mathrm{B} / \mathrm{D}=0.75 \text { (free flow } \\
& \text { entrance) } \\
& \times \mathrm{B} / \mathrm{D}=0.75 \text { (submerged } \\
& \text { flow entrance) } \\
& +\mathrm{B} / \mathrm{D}=1.33 \text { (free flow } \\
& \text { entrance) } \\
& \text { - } \mathrm{B} / \mathrm{D}=1.33 \text { (submerged } \\
& \text { flow entrance) }
\end{aligned}
$$

Figure 15. Design Chart for Aspect Ratio 0.5, 0.75 and 1.33 for submerged and unsubmerged entrance with inlet transition

\section{References:-}

1. B. Dasika "New Approach to Design of Culverts" Journal of Irrigation and Drainage Engineering, (ASCE), 121(3), 1995, pp. 261-264; DOI:10.1061/(ASCE) 0733-9437(1995) 121.3A3 (261).

2. D.A. Chin "Hydraulic Analysis and Design of Pipe Culvert: USGS versus FHWA" Journal of Hydraulic Engineering, ASCE, 139(8), 2013, pp. 886-893; DOI:10.1061(ASCE) HY.1943-7900.0000748.

3. D.H. Yoo and S. Lee "Direct Determination of the Width or the Height for a Box Culvert Applying Dimensionless Equations" KSCE Journal of Civil Engineering, 16(7), 2012, pp. 1302-1307; DOI:10.1007/S12205-012-1695-1.

4. D.J. Howes, C.M. Burt and B.F. Sanders "Subcritical Contraction for Improved Open Channel Flow Management Accuracy with an Upward looking ADVM" Journal of Irrigation and Drainage Engineering, ASCE, 136(9), 2010, pp. 617-626; DOI:10.1061/(ASCE) IR.1943-4774.0000224.

5. G.L. Bodhaine "Measurement of Peak Discharge at Culverts by Indirect Method-Chapter A3" Techniques of Water Resources Investigations of the USGS, Fifth Print, 1988.

6. J.D. Schall, R.L. Thompson, S.M. Zerges, R.T. Kilgore and J.L. Morris "Hydraulic Design of Highway Culverts" $3^{\text {rd }}$ ed., HDS5, FHWA, 2012.

7. L.G. Straub, A.G. Anderson and C.E. Bowers "Importance of Inlet Design on Culvert Capacity" Technical Paper No.13, Series B, SAFHL, University of Minnesota, 1953.

8. R.J. Charbeneau, A.D. Henderson and L.C. Sherman "Hydraulic Performance Curves for Highway Culverts" Journal of Hydraulic Engineering, ASCE, 132(5), 2006, pp. 474-481; DOI:10.1061/(ASCE) 0733-9429 (2006) 132:5 (474). 